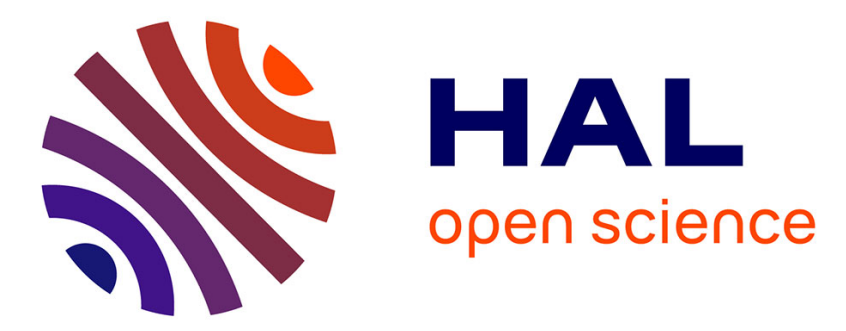

\title{
Measurement of the chemical potential of a liquid in porous media
}

Jean-Claude Benet, Alejandra Ramirez-Martinez, Francois Ouedraogo, Fabien

Cherblanc

\section{- To cite this version:}

Jean-Claude Benet, Alejandra Ramirez-Martinez, Francois Ouedraogo, Fabien Cherblanc. Measurement of the chemical potential of a liquid in porous media. Journal of Porous Media, 2012, 15 (11), pp.1019-1029. 10.1615/JPorMedia.v15.i11.30 . hal-00731124

\section{HAL Id: hal-00731124 \\ https://hal.science/hal-00731124}

Submitted on 12 Sep 2012

HAL is a multi-disciplinary open access archive for the deposit and dissemination of scientific research documents, whether they are published or not. The documents may come from teaching and research institutions in France or abroad, or from public or private research centers.
L'archive ouverte pluridisciplinaire HAL, est destinée au dépôt et à la diffusion de documents scientifiques de niveau recherche, publiés ou non, émanant des établissements d'enseignement et de recherche français ou étrangers, des laboratoires publics ou privés. 


\title{
Measurement of the chemical potential of a liquid in porous media
}

\author{
J.-C. Bénet, A. Ramirez-Martinez, F. Ouedraogo and F. Cherblanc. \\ Laboratoire de Mécanique et Génie Civil, Université de Montpellier 2, CNRS \\ Cc 048, Place Eugène Bataillon, 34095 Montpellier cedex 5, France
}

jean-claude.benet@univ-montp2.fr

tel: (33) 0467143755.

Fax (33) 0467144555

\begin{abstract}
This study deals with experimental methods dedicated to the determination of the liquid chemical potential in heterogeneous media. Various measurement techniques are proposed including a new mechanical method based on the expansion of the air-vapor atmosphere surrounding a sample. From the large range of materials under investigation (soil, wood, gel, agro-product, biological tissue), various micro-structures are investigated. Thus, liquid/solid interactions occurring at the interface scale involve several physico-chemical phenomena that can all be interpreted through the concept of chemical potential. The dependence of the liquid chemical potential on the liquid content is established over the whole range of energy. Eventually, extrapolation of the results towards the low values of chemical potential is analyzed and a modeling approach is proposed. Even if the results presented concerns essentially a water phase, the principles are applicable to several other fluids.
\end{abstract}

\section{Nomenclature}

$a_{w}:$ water activity $(/)$

$m_{i}$ : mass of the component $i(\mathrm{~kg})$

$M_{i}:$ molar mass of component $i\left(\mathrm{~kg} \cdot \mathrm{mole}^{-1}\right)$

$p_{i}:$ pressure of phase $i$ or partial pressure of $i$ in gas mixture $(\mathrm{Pa})$

$p^{+}:$reference pressure $(\mathrm{Pa})$

$p_{\text {veq }}:$ equilibrium vapor pressure $(\mathrm{Pa})$

$p_{v s}(T)$ : saturated vapor pressure $(\mathrm{Pa})$

$r$ : menisci radii of gas-water interface (m)

$R$ : ideal gas constant $\left(\mathrm{J} \cdot \mathrm{mole}^{-1} \cdot \mathrm{K}^{-1}\right)$ 


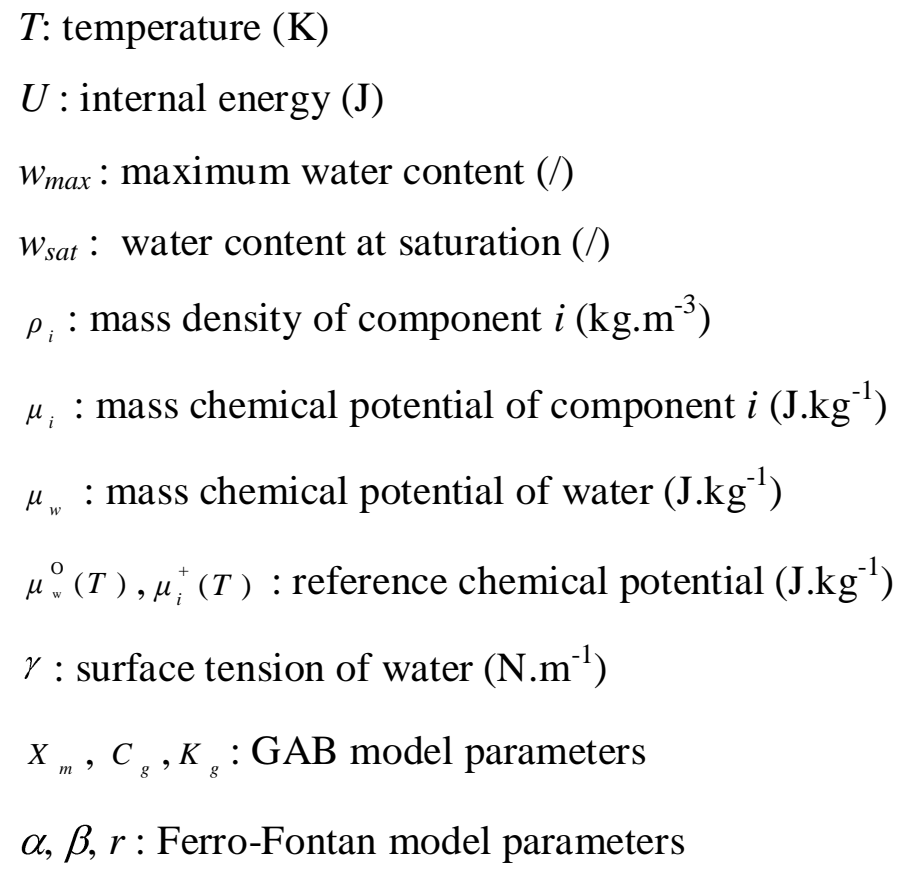

\section{Key-words}

chemical potential, tensiometry, sorption isotherm, capillarity, hygroscopicity, soils, gels, agro-products

\section{Introduction}

Heterogeneous media are characterized by the interaction of thermodynamic open subsystems, which can be assimilated to phases separated by large interfaces. These phases can possibly consist of several compounds. A large variety of material corresponds to this definition: soils which have a slightly deformable matrix, gels and pastas which can undergo large deformations, agro-products with a cellular arrangement and biological tissues which present a more complex micro-structure. Characteristic sizes of micro-structures range from millimeter (soils) to nanometer (biological tissues, gels). Therefore, the thermodynamic states of phases and constituents are significantly affected by interfacial phenomena resulting from the interaction with other constituents. While these physico-chemical interactions take place at the microscopic scale (surface tension, Van der Waals forces ...), they manifest themselves at a larger scale through usual macroscopic phenomena such as capillarity, hygroscopicity ... 
To characterize the thermodynamic state of a pure liquid phase in a heterogeneous medium, the liquid pressure can be used. When a gas phase exists, the difference between liquid- and gas-phase pressures is more appropriate leading to the definition of capillary pressure or suction. Derived from soil sciences (Fredlund and Xing, 1994), the use of these concepts is restricted to a specific geometrical configuration of the liquid phase, i.e., it assumes that water is a wetting phase and separated from gas phase by spherical interfaces with concavity directed towards the gas phase. In this capillary state, the equilibrium between phases is governed by Laplace's (Guggenheim, 1965) and Kelvin's laws (Defay et al., 1966) which depends on the meniscus radius of the liquid-gas interface. In the case of soil at low water content, the liquid phase is arranged in the form of adsorbed layers. Therefore the Laplace and Kelvin relations are no longer valid while the concept of pressure is no more appropriate to describe the state of water (Koorevaar et al., 1983; Iwata et al., 1995; Baker and Frydman, 2009). Furthermore, since the liquid phase may be discontinuous in such configurations, the consistency of a macroscopic pressure is questionable. However, these macroscopic concepts have been largely extended to various materials and situations without any thorough investigation of their validity. For instance, in gels, agro-products and biological tissues, the physical properties of the liquid phase strongly depend on the liquid-solid interfaces and measuring the pressure of the liquid phase is practically unfeasible.

An alternative to characterize the thermodynamic state of a component is to rely on the chemical potential (Edlefsen and Anderson, 1943; Low, 1961; Nitao and Bear, 1996). The chemical potential represents the mechanical energy required to remove adiabatically a unit mass of water from the media. This physical potential presents the same generality in mass transport as the temperature in heat transport. Although this thermodynamic function comes from classical physics, it is still "a quantity in search of recognition" (Job and Hermann, 2006). At thermodynamic equilibrium, the chemical potential of a constituent is identical in all parts in contact trough semi-permeable membranes. It can be defined for a constituent belonging to several phases or regions as for instance in agro-products where water can be intra or extracellular. Therefore, the opportunity to have a unique continuous potential over various phases makes it the appropriate state function for homogenization procedures.

The definition of chemical potential based on energy considerations confirms its generality useful in several research fields, particularly when dealing with coupled transport phenomena. For instance, the chemical potential gradient is the driving force governing diffusive and 
convective mass transport (Müller, 2001) while the phase change kinetics depends on the chemical potential jump across a liquid/gas interface (Bénet et al., 2009). It can adequately describe the coupling effects between transport phenomena and mechanical behavior in gels (Sih and Michopoulos, 1986; Mrani et al., 1994). As the chemical potential provides information on water availability, it governs the development of micro-organisms in food products creating a link between mechanical and biological issues. Environmental sciences are also concerned since the chemical potential contributes to represent nutrients exchanges between plants and soil, describe water transport in arid regions or evaluate the binding energies required for the extraction of hazardous substances in soils.

Choosing the chemical potential to characterize the thermodynamic state requires the development of appropriate experimental devices for its measurement. This can be carried out based on a novel interpretation of classical results obtained with existing methods (saturated salt solutions method, tensiometry). To avoid some drawbacks associated with these techniques, we also present a mechanical method recently developed (Ouoba et al., 2010). These devices have been used to characterize the thermodynamic state of water in a large variety of porous media: soils, wood, gel and agro-products. The objectives is to show that the concept of chemical potential can help drawing some links between multiple experimental results so as to set up unified vocabulary and definition.

\section{Chemical potential of a constituent in a heterogeneous media}

\subsection{Theoretical background}

In 1875, Gibbs introduced the concept of chemical potential to describe systems of variable composition. It is defined as the partial derivative of the internal energy $(U)$ with respect to the mass of the component $\left(m_{i}\right)$ while entropy $(S)$, volume $(V)$ and mass of other constituents $\left(m_{j}\right)$ remain constant (Guggenheim, 1965) (Eq. 1).

$$
\mu_{i}=\left(\frac{\partial_{U}}{\partial m_{i}}\right)_{V, S, m_{j ; j} j_{i}}
$$


The fundamental property of chemical potential stipulates that, during a natural transformation at constant temperature, a compound moves from regions where its chemical potential is high to regions where its value is low. When a constituent $i$ is present in both phases $\alpha$ and $\beta$, separated by a membrane permeable only to constituent $i$, the thermodynamic equilibrium is characterized by (Guggenheim, 1965):

$$
\left(\mu_{i}\right)_{\text {in phase } \alpha}=\left(\mu_{i}\right)_{\text {in phase } \beta}
$$

For an incompressible pure liquid phase, the mass chemical potential is given by (Guggenheim, 1965):

$$
\mu_{i}=\mu_{i}^{+}(T)+\frac{p_{i}^{-} p^{+}}{\rho_{i}}
$$

where $\mu_{i}^{+}(T)$ is a reference value which only depends on temperature $T, p_{i}$ is the liquid pressure, $p^{+}$is a reference pressure and $\rho_{i}$ represents the mass density. When considering ideal gas mixture, it becomes (Guggenheim, 1965):

$$
\mu_{i}=\mu_{i}^{-}(T)+\frac{R T}{M_{i}} \ln \frac{p_{i}}{P^{-}}
$$

where $p_{i}$ is the gas partial pressure, $P^{-}$a reference pressure, $M_{i}$ the molar mass, $R$ the ideal gas constant, $T$ the temperature and $\mu_{i}^{-}(T)$ a reference chemical potential which only depends on temperature.

\subsection{Chemical potential measurement in heterogeneous media}

Methods of chemical potential determination are based on the fundamental property (Eq. 2). At equilibrium, the evaluation of the chemical potential in one part of the system also gives its value in the rest of the system. Therefore, the part used to evaluate its value becomes the measurement device. 


\subsubsection{Tensiometry}

The principle of tensiometry is outlined in Fig. 1. In the case of a soil partially saturated by a water phase, the porous plate behaves as a semi-permeable membrane. According to Eqs. 2 and 3 , the measurement of the liquid pressure leads to identify the water chemical potential in the soil. The reference state generally corresponds to "free" water at the atmospheric pressure.
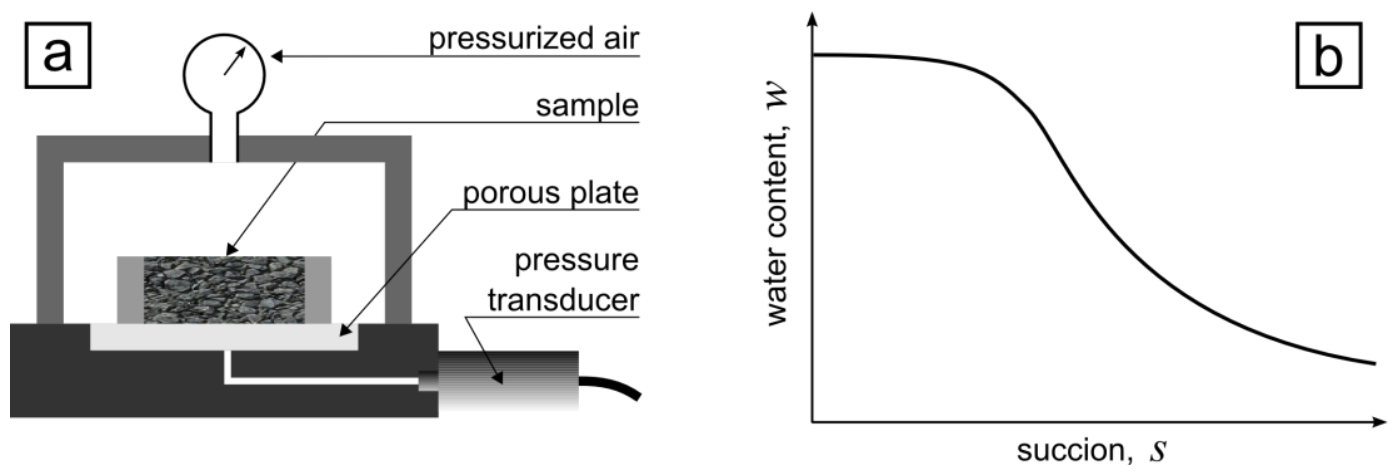

Fig. 1. Determination of water chemical potential in a porous sample by tensiometry. a) experimental device. b) soil-water characteristic curve.

The measurement range of tensiometry is restricted, first, by the difficulty to ensure a perfect continuity of the water phase through the porous plate and, second, by the water cavitation occurring at low pressure. Therefore, to widen the measurement range towards higher values of chemical potential, a gas over-pressure can be applied since authors focus on the suction defined as the gas/liquid pressure difference (Salager et al., 2010). The maximum overpressure is called the entry pressure above which the gas-phase percolates though the porous stone and violates hypothesis (Morel-Seytoux et al., 1996). This offset technique regularly leads to publish experimental results on a large suction range from $1 \times 10^{2}$ to $5 \times 10^{5} \mathrm{~Pa}$ (Fredlund and Xing, 1994; Leong \& Rahardjo, 1997; Salager et al., 2010). However, liquid relative pressure values below $-10^{5} \mathrm{~Pa}$ should be carefully interpreted (Baker et al., 2009). From our mind, the concepts of pressure field or capillary potential are meaningless in these configurations and cannot support any physical interpretation of micro-scale phenomena.

\subsubsection{Sorption isotherm}

Methods based on the sorption isotherm (Fig. 2) consist in establishing a thermodynamic equilibrium between the liquid water adsorbed in the sample and the surrounding water vapor. 
The vapor partial pressure is regulated by standard saturated salt solutions (SSS) while the sample external surface behaves as a semi-permeable membrane for water. At constant temperature, the water chemical potential is evaluated from the vapor partial pressure $p_{v e q}$ (Eq. 4) where the reference state is given by "free" water characterized by a saturated vapor pressure $p_{v s}(T)$. Thus, the deviation of water chemical potential $\mu_{w}(T)$ is given by:

$$
\mu_{w}(T)^{-} \mu_{w}^{\mathrm{o}}(T)=\frac{R T}{M_{w}} \ln \left(a_{w}\right)
$$

where the water activity $a_{w}$, is defined by:

$$
a_{w}=\frac{p_{v e q}}{p_{v s}(T)}
$$

This method is accurate only if the deviation of the vapor partial pressure compared to the saturated vapor pressure is significant, i.e., for activity values below 0.95. Indeed, the contraction of chemical potential scale around high activities done by logarithm operator (Eq. 5) hides most of capillary effects. Therefore, this method is used to complete the results given by tensiometry. However, as discussed in section 3, the measurement ranges of both methods do not overlay and requires extrapolation to propose a continuous modeling.
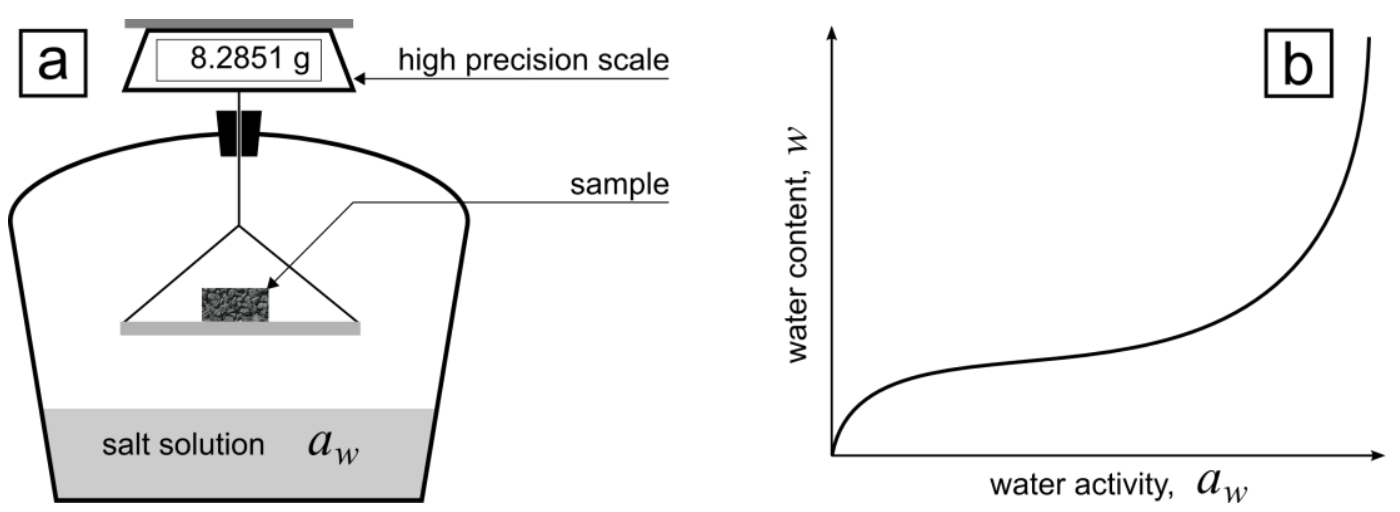

Fig. 2. Determination of water chemical potential in a porous sample using saturated salt solutions. a) experimental device. b) sorption isotherm curve. 


\subsubsection{Mechanical method}

To overstep the limitations of previous technique, a new method was developed recently able to measure the chemical potential of any volatile compound adsorbed in a porous sample (Ouoba et al., 2010). Also based on vapor-liquid equilibrium between sample and its surrounding atmosphere, this technique aims to measure the vapor partial pressure instead of imposing it. The sample is placed in a thermo-regulated sealed chamber whose volume variations are controlled by the displacement of a piston (Fig. 3a). Successive volume increments are carried out while the temperature and total gas pressure are recorded at each equilibrium stage (Fig. 3b). By relying on the ideal gas law, the total gas pressure at the $i^{\text {th }}$ equilibrium stage, $p_{g}^{i}$, can be written as:

$$
p_{g}^{i}=p_{v}^{i}+n_{a} \frac{R T}{v_{o}+i \times \Delta v}
$$

where $v_{o}$ is the initial volume occupied by the gas phase, $\Delta v$ is the volume increment, $n_{a}$ is the moles number of air in the system and $p_{v}^{i}$ is the vapor partial pressure at the $i^{\text {th }}$ equilibrium stage. If the volume increment, $\Delta v$, is low, the water content, $w$, weakly varies throughout the experiment and the vapor pressure $p_{v}^{i}$ can be regarded as the equilibrium partial pressure, $p_{v e q}$. Thus, the determination of the 3 unknowns, $p_{v e q}, v_{o}$ and $n_{a}$, can be achieved from 3 equilibrium stages. To increase accuracy, 8 volume increments are carried out and the problem is solved using a nonlinear least-squares minimization procedure based on the standard Levenberg-Marquadt algorithm. Finally, the chemical potential is calculated using Eqs. (5) and (6) at the temperature of the experiment. 

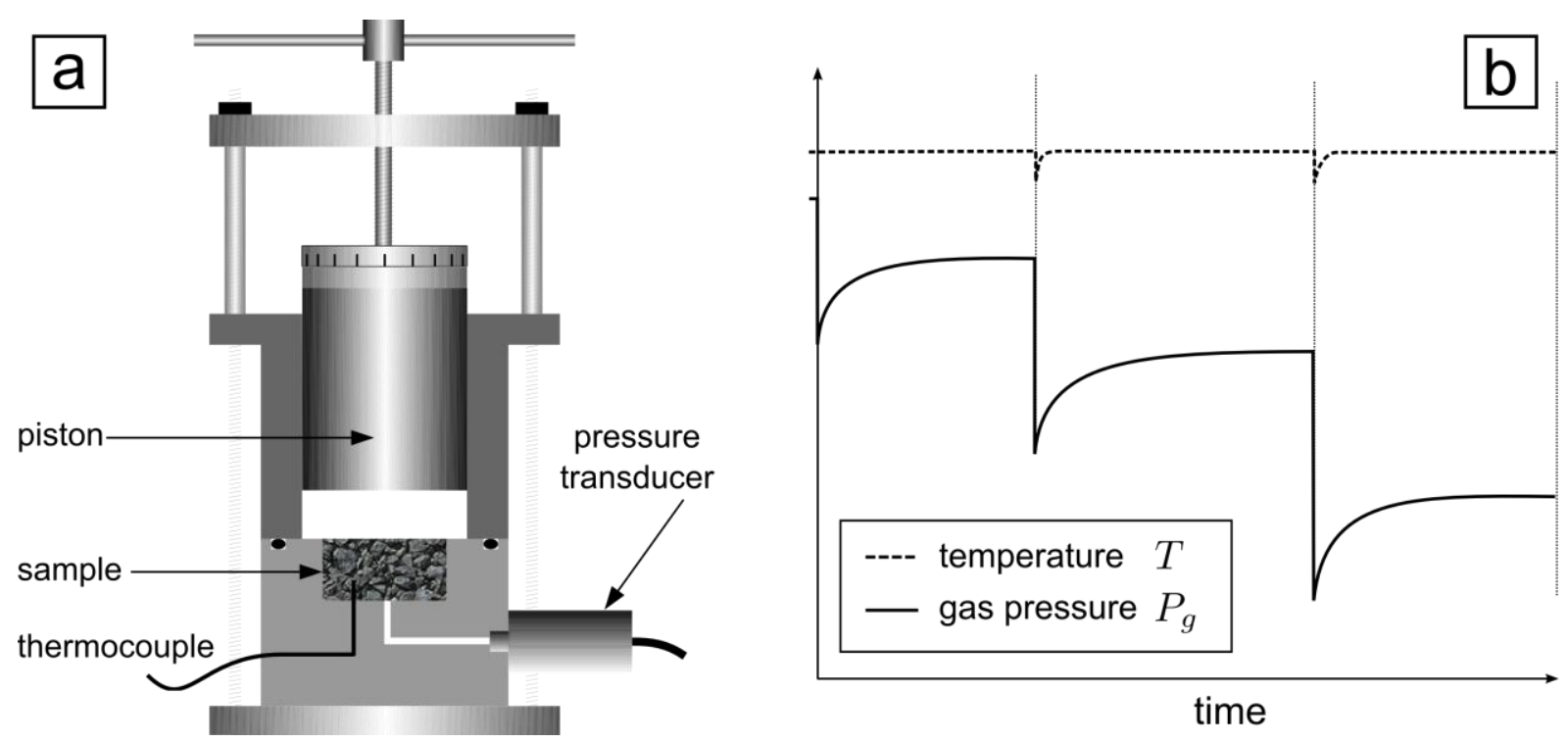

Fig. 3. Determination of water chemical potential in a porous sample using the mechanical method. a) experimental device. b) evolution of pressure and temperature versus time during one measure.

The accuracy of this method have been numerically estimated and validated using standard saturated salt solutions at $30^{\circ} \mathrm{C}$ (Ouoba et al., 2010). The main advantage of this method is to be usable with any volatile compound (VOC, hydrocarbon, solvent, etc.) and is not restricted to water like standard protocols. When dealing with water, this method is faster and gives directly the chemical potential without relying on the prior determination of the complete sorption isotherm. Furthermore, the application range is slightly widened when compared to the SSS method, specifically towards high activity values. This advantage will be discussed in section 5 and its relevance for porous media characterization will be highlighted.

\section{Liquid chemical potential in various materials}

Table 1 summarizes the characteristics of materials under investigation. These include three different types of soils, several biological products and gels at temperature from $20^{\circ} \mathrm{C}$ to $80^{\circ} \mathrm{C}$ using the three measurement methods presented in previous section. The maximum moisture content $w_{\max }$ is also given in column 7 . For slightly deformable materials such as soil or wood, this value corresponds to the water content at saturation, while in highly deformable media such as latex, pasta, cocoa and coffee bean, it represents the maximum experimentally reported. 


\begin{tabular}{|c|c|c|c|c|c|c|}
\hline Material & Reference & Temperature & Method & Structure & Liquid & $w_{\max }$ \\
\hline Silt (France) & $\begin{array}{l}\text { Jamin, 2004; } \\
\text { Salager, } 2010\end{array}$ & $30^{\circ} \mathrm{C}$ & $\begin{array}{l}\text { tensiometry, } \\
\text { SSS }\end{array}$ & granular, triphasic & water & 0.29 \\
\hline Silt (France) & $\begin{array}{l}\text { Ouoba, 2010; } \\
\text { this study }\end{array}$ & $30^{\circ} \mathrm{C}$ & $\begin{array}{l}\text { mechanical } \\
\text { method }\end{array}$ & granular, triphasic & heptane & 0.18 \\
\hline Silt (France) & $\begin{array}{l}\text { Ouoba, 2010; } \\
\text { this study }\end{array}$ & $30^{\circ} \mathrm{C}$ & $\begin{array}{l}\text { mechanical } \\
\text { method }\end{array}$ & granular, triphasic & $\begin{array}{l}\text { trichloro } \\
\text { ethylene }\end{array}$ & 0.42 \\
\hline $\begin{array}{l}\text { Sand ( Burkina- } \\
\text { Faso) }\end{array}$ & This study & $30^{\circ} \mathrm{C}$ & $\begin{array}{l}\text { tensiometry, } \\
\text { SSS }\end{array}$ & granular, triphasic & water & 0.26 \\
\hline Clay (France) & $\begin{array}{l}\text { Jamin, 2004; } \\
\text { Salager, } 2010\end{array}$ & $30^{\circ} \mathrm{C}$ & $\begin{array}{l}\text { tensiometry, } \\
\text { SSS }\end{array}$ & granular, triphasic & water & 0.34 \\
\hline Latex & Auria, 1991 & $60^{\circ} \mathrm{C}$ & SSS & $\begin{array}{l}\text { continuous solid phase, } \\
\text { biphasic }\end{array}$ & water & ? \\
\hline Wood & Anoua, 1986 & $60^{\circ} \mathrm{C}$ & SSS & $\begin{array}{l}\text { continuous solid phase, } \\
\text { triphasic }\end{array}$ & water & 0.4 \\
\hline Alumina gel & Pillard, 1997 & $30^{\circ}$ & SSS & $\begin{array}{l}\text { granular, triphasic for } \\
w>1 \text { and biphasic for } \\
w<1\end{array}$ & water & $>2.6$ \\
\hline Agar gel & Mrani, 1995 & $30^{\circ} \mathrm{C}$ & SSS & $\begin{array}{l}\text { continuous solid phase, } \\
\text { biphasic }\end{array}$ & water & $>10$ \\
\hline Pasta & Ponsard, 2003 & $20^{\circ} \mathrm{C}, 80^{\circ} \mathrm{C}$ & SSS & $\begin{array}{l}\text { continuous solid phase, } \\
\text { biphasic }\end{array}$ & water & $>1$ \\
\hline $\begin{array}{l}\text { Cacao bean } \\
\text { (Mexico) }\end{array}$ & Augier, 1999 & $40^{\circ} \mathrm{C}$ & SSS & cellular, biphasic & water & 0.95 \\
\hline $\begin{array}{l}\text { Coffee bean } \\
\text { (Mexico) }\end{array}$ & this study & $35^{\circ} \mathrm{C}$ & $\begin{array}{l}\text { SSS, } \\
\text { mechanical } \\
\text { method }\end{array}$ & cellular, biphasic & water & 1.5 \\
\hline
\end{tabular}

Table 1: Materials under investigation

Since the reference state corresponds to "free" water at the atmospheric pressure, the chemical potential of liquid adsorbed in porous materials is negative, i.e., some energy is required $(d U>0)$ to extract water from the sample $(d m<0)$. To simplify the following discussions, we will systematically refer to the absolute value of the chemical potential: $\left|\mu_{w}\right|$. 
In Figs. 4 to 6, the variation of absolute value of the liquid chemical potential is plotted as a function of the liquid content. In spite of the large variety of micro-structures, similar plots are observed. These curves decrease monotonically as the liquid content increases. For low values of liquid content, the liquid activity tends to 0 and from Eq. (5), $\left|\mu_{w}\right|$ tends to $\infty$.

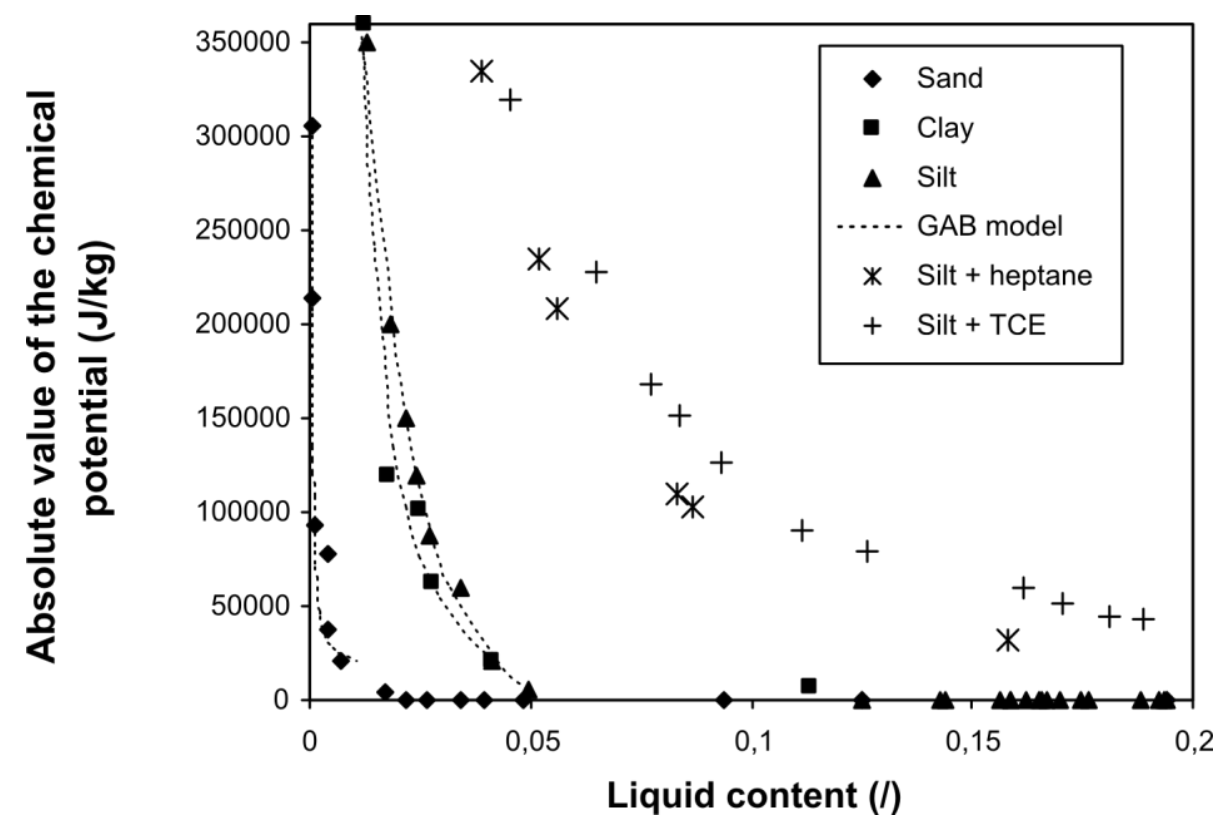

Fig. 4. Variation of the absolute value of the chemical potential as a function of water content. Comparison between experimental values and $\mathrm{GAB}$ model for various soils.

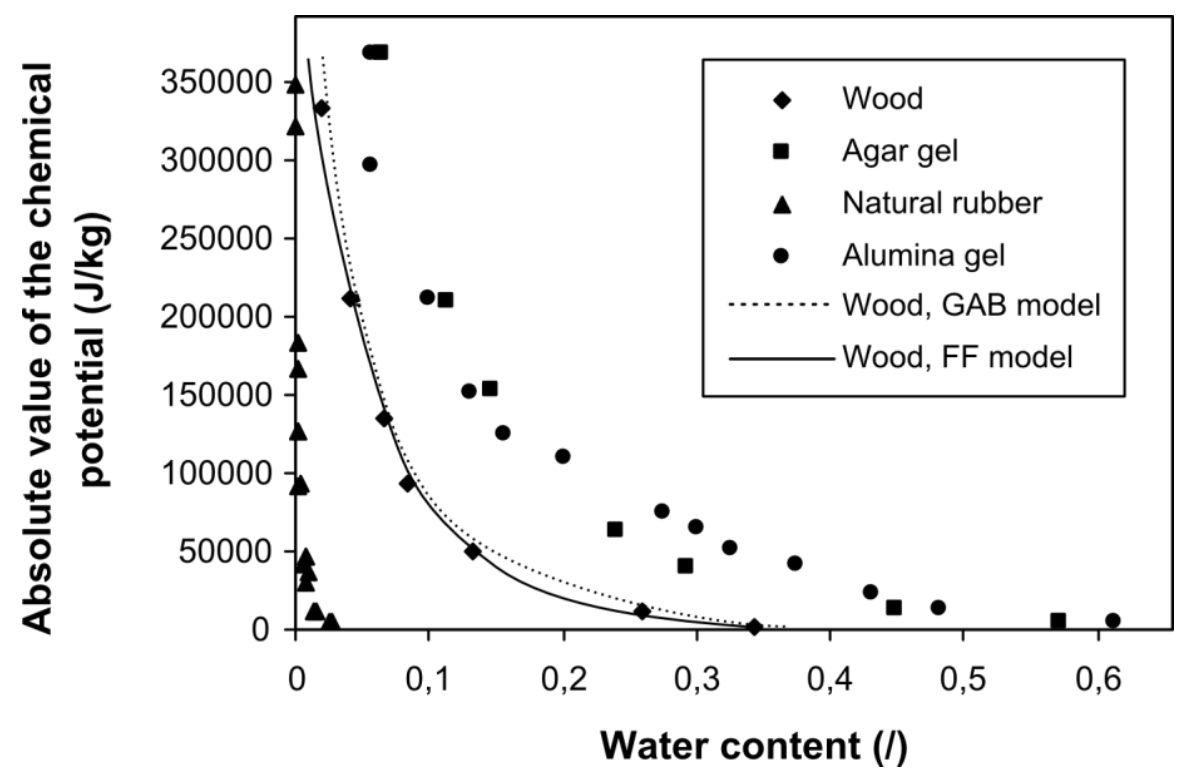

Fig. 5. Variation of the absolute value of the chemical potential as a function of water content. Comparison between experimental values, GAB and FF model for wood and coffee. 


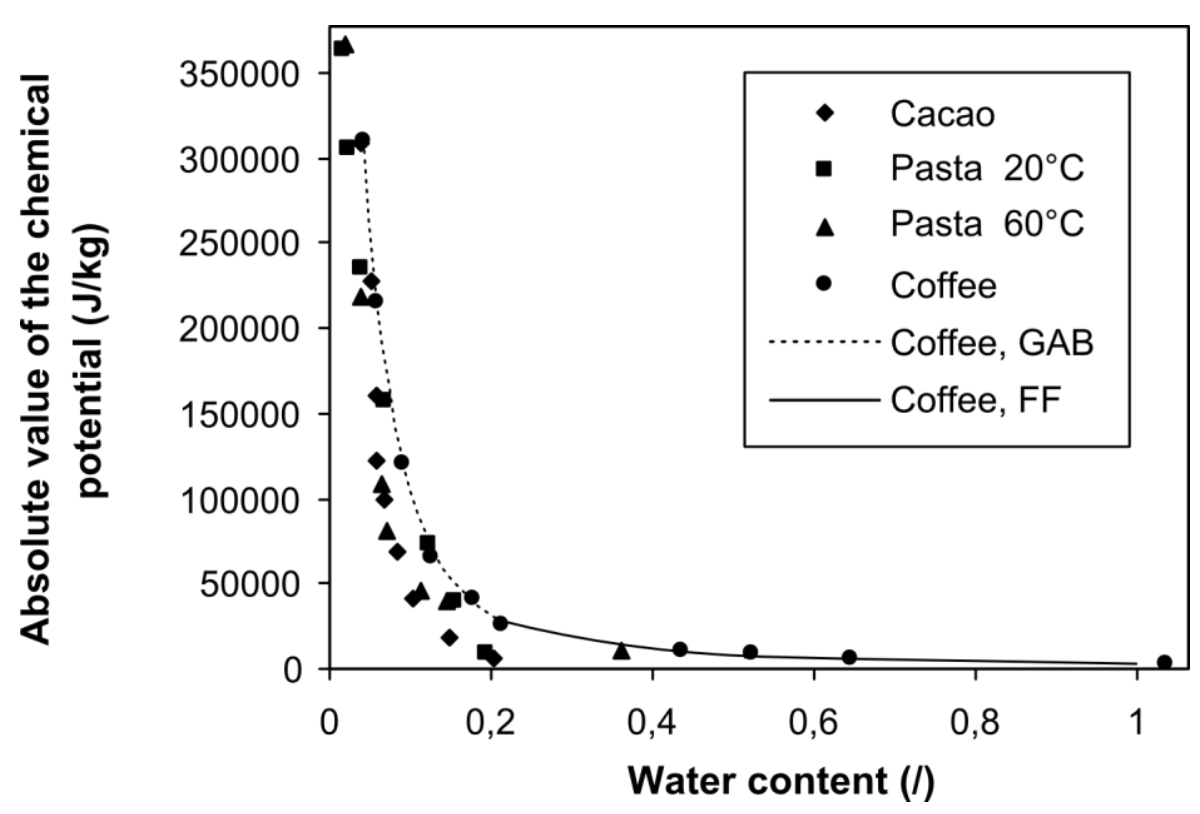

Fig. 6. Variation of the absolute value of the chemical potential as a function of water content. Comparison between experimental values, GAB and FF model for various agro-products.

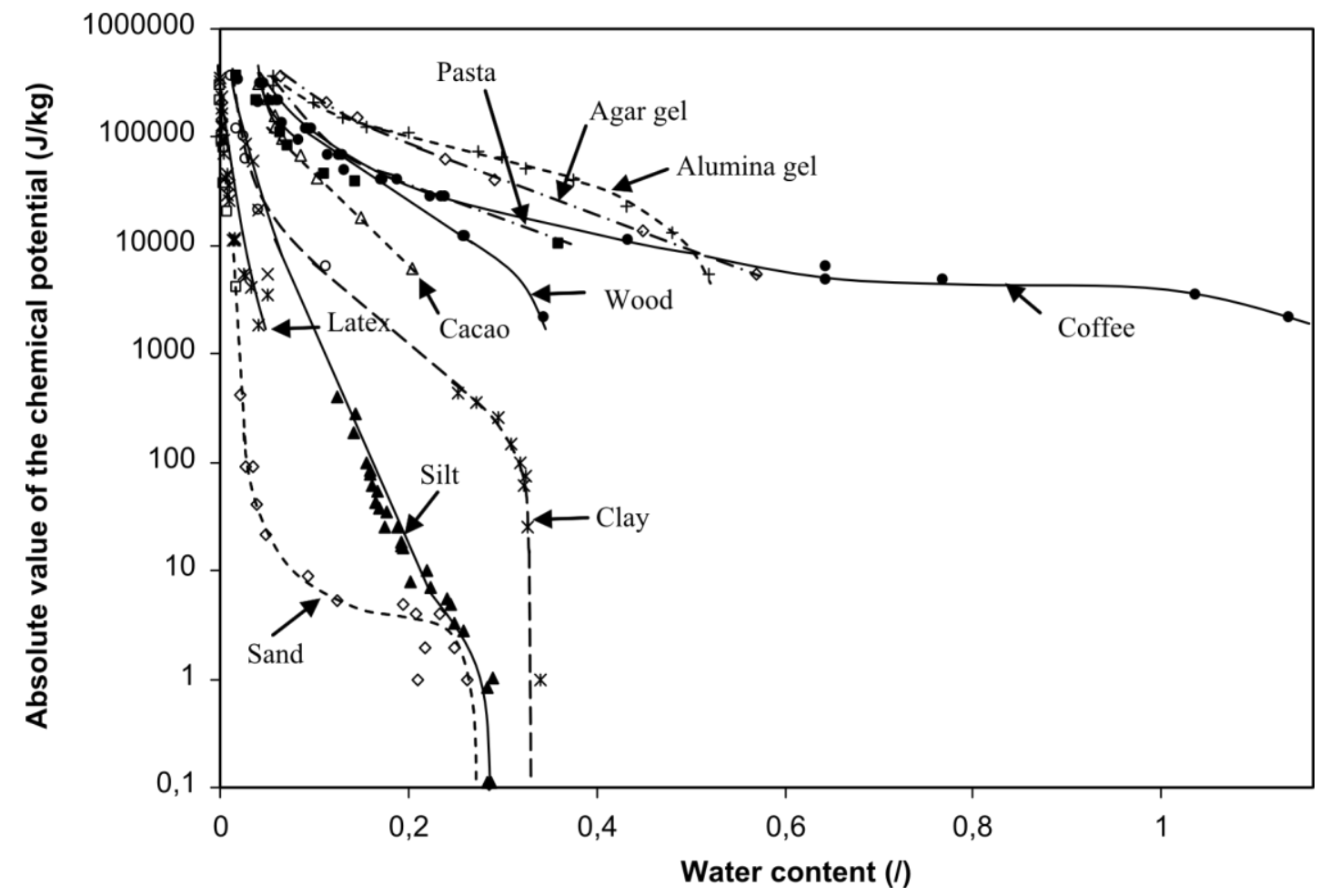

Fig. 7. Variation of the absolute value of the chemical potential as a function of water content for various materials using a logarithmic scale.

A representation of these curves using a logarithmic scale is given in Fig. 7. Lower values of chemical potential, $\left|\mu_{w}\right| \in[0.1,500]$, are measured by tensiometry while greater values, 
$\left|\mu_{w}\right| \in[5000,500000]$, are obtained using SSS and mechanical method. These curves can be fairly interpolated in the range [500, 5000] as none of the methods are useable (Fig. 7). In civil and petroleum engineering (Fredlund and Xing, 1994) or in agronomy, these curves are usually designated by the term "soil-water characteristic curve" or "capillary pressure curve" in which the chemical potential is translated in a liquid pressure, $p_{w}$, by means of Eq. (3). This representation in term of pressure assumes a spherical liquid/gas interface over the full range of water content and is described by the Laplace's equation:

$$
\mu_{w}=\frac{p_{w}-p_{a t m}}{\rho_{w}}=-\frac{2 \gamma}{\rho_{w} r}
$$

where the surface tension for water is $\gamma=73 \times 10^{-3} \mathrm{~N} \cdot \mathrm{m}^{-1}$. Large values of $\left|\mu_{w}\right| \geq 5000 \mathrm{~J} \cdot \mathrm{kg}^{-1}$ corresponds to menisci radii lower than $r \leq 3 \times 10^{-8} \mathrm{~m}$. Such liquid/gas interface radius, about 100 water molecule size, is the limit of validity of geometrical model associated with capillary interfaces (Baker and Frydman, 2009). Therefore, the concept of capillary pressure is meaningless in the upper part of Fig. 7, i.e., when most of the water is adsorbed on the solid surface. In this case, the concavity of liquid/gas interfaces is turned towards the liquid-phase meanwhile Eq. (8) is only valid for a spherical liquid/gas interface whose concavity is directed towards the gas-phase. The classical theory based on capillary effects leads to misinterpretations and cannot be extended without careful investigation. Since it is an energetic concept, the chemical potential is not subjected to this restriction and can consistently describe the thermodynamic state of water over the whole range of water content.

\section{Modeling of the chemical potential curves}

To curve-fit the experimental variation of chemical potential as a function of water content, several models have been proposed in the literature. For instance, the GAB model relates the water content, $w$, to the water activity, $a_{\mathrm{w}}$, by (Timmermann el al., 2001; Escalona et al., 2008):

$$
w=\frac{X_{m} C_{g} K_{g}}{\left(1-K_{g} a_{w}\right)\left[1+\left(C_{g}-1\right) K_{g} a_{w}\right]} a_{w}
$$


where $X_{m}, C_{g}$ and $K_{g}$ are adjustment parameters given in Tab. 2. The corresponding plots are represented in Figs. 4 to 6. Since this model has been developed to describe specifically the multilayer adsorption isotherm at low water content, a good correlation is observed for high values, $\left|\mu_{w}\right| \geq 10000 \mathrm{~J} \mathrm{~kg}^{-1}$, while it completely fails to describe the low values of $\left|\mu_{w}\right|$ (Figs. 4 to 6). In soils, theses discrepancies result from the predominance of capillary effects for large water content. However, this reason cannot be propounded for agro-products since biphasic configurations are observed over the full range of water content, i.e., capillary effects are insignificant.

\begin{tabular}{|l|l|l|l|}
\hline Material & $X_{m}$ & $C_{g}$ & $K_{g}$ \\
\hline Sand & 0,00050321 & 11,3738193 & 1,10150468 \\
\hline Silt & 0,0197384 & 24,4412497 & 0,63838456 \\
\hline Clay & 0,01407112 & 57,4857959 & 0,77615667 \\
\hline Wood & 0,06258278 & 4,71419126 & 0,85103896 \\
\hline Coffee & 0,06323387 & 12,777643 & 0,87091313 \\
\hline
\end{tabular}

Table 2: GAB parameters

At lower values, the Ferro-Fontan (FF) model is more appropriate (Ferro-Fontan et al., 1982; Baucour et al., 2000).

$$
\ln \left(\frac{\beta}{a_{w}}\right)=\alpha w^{-r}
$$

where $\alpha, \beta$ and $r$ are adjustable parameters (Tab. 3). When $a_{w} \rightarrow 1$ as $\mu_{e} \rightarrow 0$, the water content tends towards a limit, $w^{\rightarrow} w_{\text {lim }}$. Considering Eq. (5), the FF model allows expressing the water chemical potential as:

$$
\mu_{w}=-\frac{\alpha R T}{M_{w}}\left(w^{-r}-w_{\text {lim }}{ }^{-r}\right) \quad \text { with } \quad w_{\text {lim }}=\left(\frac{\ln \beta}{\alpha}\right)^{-\frac{1}{r}}
$$


The relevance of this limit water content will be discussed in the next section. Some representations of FF model are given in Figs. 4 to 6.

\begin{tabular}{|l|l|l|l|l|l|l|}
\hline Material & $\alpha$ & $\beta$ & $r$ & $\begin{array}{l}w_{\text {limit }} \\
\text { oven method }\end{array}$ & $\begin{array}{l}w_{\text {limit }} \\
\text { linearization }\end{array}$ & $\begin{array}{l}w_{\text {limit }} \\
\text { Ferro- Fontan }\end{array}$ \\
\hline Sand & 0,0041625 & 1,0043 & 0,02234 & 0,26 & 0,27 & 0,257 \\
\hline Silt & $7,75 \mathrm{E}-05$ & 1,00293324 & 2,0868 & 0,29 & 0,29 & 0,175 \\
\hline Clay & $-0,642$ & 0,9956 & $-4,4991$ & 0,34 & 0,33 & 0,33 \\
\hline Wood & 0,2298 & 1,5627 & 0,651 & $<0.40$ & 0,34 & 0,36 \\
\hline Coffee & 0,0363 & 1,0139 & 1,123 & 1,5 & 1,5 & 2,365 \\
\hline
\end{tabular}

Table 3: Ferro-Fontan parameters

\section{The case of biological material at high activity}

Although the range of lowest values, $\left|\mu_{w}\right| \in[0,5000]$, remains small when compared to the total variation observed in Fig. 7, $\mu_{w} \mid \in[0,500000]$, this activity range is of first importance when dealing with biological materials. For instance, most of microorganisms develop at high water activities, $0.9 \leq a_{w} \leq 1$, i.e., $0 \leq\left|\mu_{e}\right| \leq 15000$. In agriculture and farming, appropriate plant growth is conditioned by high water activities in soils. Furthermore, with many agroproducts, experimental values significantly diverge from the GAB model when water activity is greater than 0.95 (Baucour et al., 2000).

This range is not easily accessible with the SSS method. Indeed, few saline solutions allow an accurate regulation of the relative humidity between $90 \%$ and $100 \%\left(\mathrm{KNO}_{3}: 91 \% ; \mathrm{K}_{2} \mathrm{SO}_{4}\right.$ : 96\%). Furthermore, in this range of humidity, equilibrating the sample with its surrounding atmosphere can require about one month and product denaturizing can generally not be avoided. In soil sciences, this range is generally characterized by means of tensiometry. Nevertheless, this method requires perfect liquid-phase continuity between sample and device what is hardly achieved with biological materials.

Therefore, to explore this range of chemical potential in biological materials and agroproducts, new measurement techniques have been developed. The device developed by Baucour et al. (2000) uses a vapor saturated air flow subjected to successive calibrated 
pressure drops. It can accurately regulate water activities up to 0.98. In a similar trend, the mechanical method (Ouoba et al, 2010) presented above is of first interest. Indeed, water activities up to 0.985 have been measured in the case of green coffee beans.

To characterize the whole curve (Fig. 7), the major issue is to estimate the limit reached by the water content as the chemical potential tends towards 0 , namely $w_{\text {limit. }}$ It corresponds to the intersection of the curve plotted in Figs. 4 to 6 with the $x$-axis. A zoom on low chemical potential measured in various soils is proposed in Fig. 8. It clearly shows that a linear description is a fair approximation in this range and unambiguously defines the limit water content, $w_{\text {limit. }}$ In the case of soils, it is equivalent to the saturated water content (Tab. 1) and can be directly linked to the porosity since sample deformation is not considered.

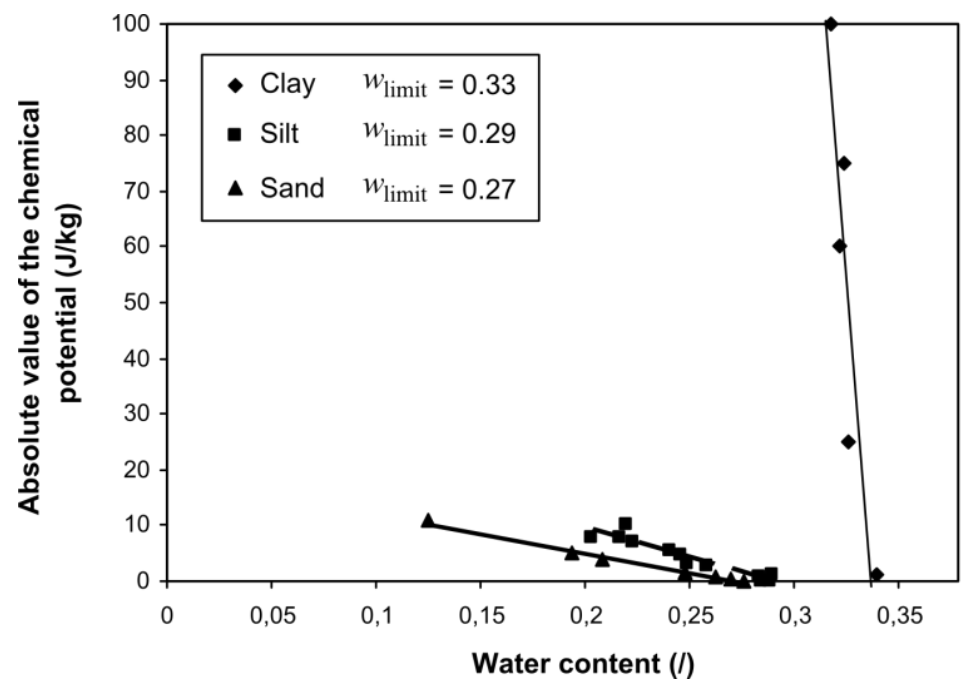

Fig. 8. Variation of the absolute value of the chemical potential as a function of water content for three soils at low chemical potential.

Consequently, we propose to extrapolate the data obtained from biological materials using a linear modeling. This is done in Fig. 9 in the case of wood and coffee. It is interesting to notice that the water content at saturation of a coffee grain is around 1.5 (Tab. 1) which corresponds to the limit water content, $w_{\text {limit }}$, given by this method. For wood, the limit water content, $w_{\text {limit }}$, is close to the fiber saturation point usually taken as 0.3 . 


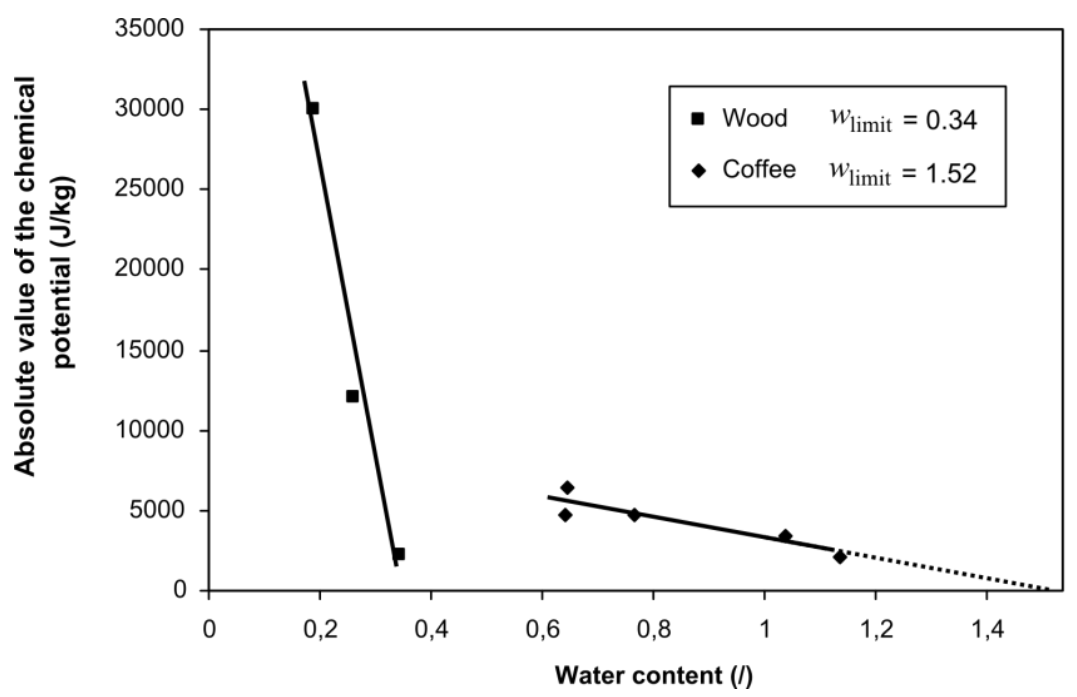

Fig. 9. Variation of the absolute value of the chemical potential as a function of water content for wood and coffee at low chemical potential. Determination of $w_{\text {limit }}$.

In logarithmic scale, the adequacy of a linear approximation is assessed in Fig. 10 for a large range of materials. When compared to the FF model (Eq. 11), small discrepancies are observed even if the linear approximation relies on 2 adjustable parameters while the FF model needs 3 parameters. The interest of such description is to clarify the vertical asymptote of the chemical potential at very low values observed with a logarithmic scale.

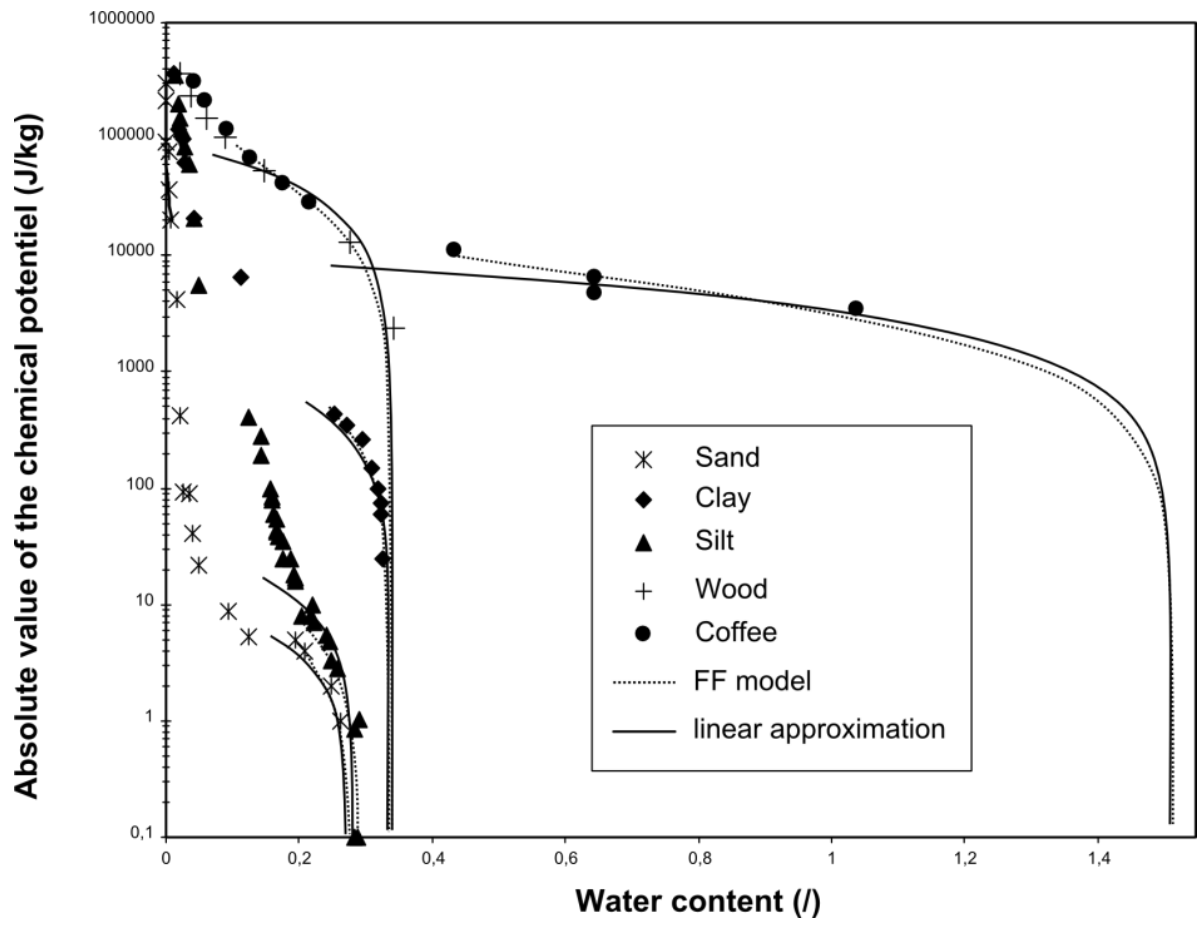

Fig. 10. Comparison between experimental values, Ferro-Fontan model and linear approximation. 


\section{Conclusions}

The chemical potential is a powerful concept to characterize the thermodynamic state of water in porous materials regardless of micro-structure and phases distribution. It includes the concept of liquid pressure and proposes an energetic extension when solid/liquid micro-scale interactions predominate. As a homogeneous macroscopic characteristic, its interpretation makes no assumptions on the geometric distribution of the liquid phase in the media.

The association of three experimental methods (tensiometry, saturated salt solutions and mechanical method) allows the measurement of chemical potential over a wide range of water content whatever the material under investigation, from soils to agro-products. The variation of chemical potential as a function of water content shows a characteristic shape. It tends to minus infinity as the water content goes to zero and the low values defines the limit water content, $w_{\text {limit }}$, above which water can be considered as "free".

Nevertheless, the case of agro-products at high water content needs careful investigation since standard characterization methods fail to explore the lower range of chemical potential. Indeed, the liquid-phase continuity required by tensiometry is hardly achieved with biological materials and few salt solutions allow an accurate regulation of high relative humidity. Furthermore, even with the widely used GAB description, experimentally measured values significantly diverge from this model for water activities larger than 0.95.

Thus, the mechanical method associated with a linear extrapolation of chemical potential towards the lowest values has shown to be a promising alternative. Most of all, this method is much faster than standard protocols based on saturated salt solutions allowing to avoid degradation of biological media generally observed at high water activities. One major advantage of this technique is to be useable with various volatile compounds (hydrocarbon, contaminant, NAPL) opening novel perspectives in soil and environmental sciences.

The concept of chemical potential associated with practical and well-tried characterization methods aims at proposing a unifying point of view to describe the thermodynamic state of a liquid phase in a porous material. Since this concept is transversal to several application areas dealing with porous media (civil, petroleum and food engineering, biology), the underlying physical phenomena have been described using multiple definitions (matrix potential, suction, 
capillary pressure, activity ...), each of them being specific to its research domain. Therefore, this is a major issue to propose unified vocabulary and description that would facilitate scientific exchanges and multi-disciplinary approaches in porous media sciences. It should support the joint use of knowledge and expertness collected in each research area.

This concept coming directly from thermodynamics principles ensures a coherent framework to develop theoretical modeling or experimental interpretation. This would be the appropriate alternative to concepts that have ambiguous physical meanings. For instance in unsaturated soil, suction greater than $10^{5} \mathrm{~Pa}$ is physically incongruous while it is commonly used in soil sciences. Besides, the interpretation of such measures based on Laplace's equation involves so small gas/liquid interfaces radii that it reaches the limit of continuum mechanics. Such experimental observations can be correctly interpreted by relying on short-range interactions at the scale of the solid/liquid interface as done in adsorption theory. Thanks to its energetic definition, the chemical potential proposes a continuous physical description from capillary to adsorption effects.

This communication only focuses on the equilibrium state of liquid phases; however, a similar discussion can be proposed when dealing with mass transfer in porous media. Indeed, as established with Thermodynamics of Irreversible Processes ideas, the generalized forces that govern mass transfers are chemical potential differences (gradient and interface jump). By adopting this point of view, various mass transport phenomena can be integrated in a unique formulation (Darcy's flow, diffusion, osmosis, phase change ...) emphasizing the relevance of the chemical potential.

\section{References}

Augier, F., Nganhou, J., Bénet, J.-C., Berthomieu, G., and Barel, M., Experimental study of matter transfer in cocoa beans during fermentation and drying, Drying Technology, vol. 17, pp. 1027-1042, 1999.

Auria, R., Bénet, J.-C., Cousin, B., and Sainte-Beuve, J., Drying of natural rubber in sheet form internal structure and water transfer, Journal of Natural Rubber Research, vol. 6, pp. 267-280, 1991. 
Baucour, P., and Daudin, J.D., Developpement of a new method for fast measurement of water sorption isotherms in the high humidity range, validation on gelatine gel, Journal of Food Engineering, vol. 44, pp. 97-107, 2000.

Baker, R., and Frydman, S., Unsaturated soil mechanics Critical review of physical foundations, Engineering Geology, vol. 106, pp. 26-39, 2009.

Bénet, J.-C., Lozano, A.-L., Cherblanc, F., and Cousin, B., Phase change of water in hygroscopic porous medium. Phenomenological relation and experimental analysis for water in soil, Journal of Non-Equilibrium Thermodynamics, vol. 34, pp. 133-153, 2009.

Defay, R., Prigogine, P., Belleman, A., and Everett, D.,H., Surface tension and adsorption, Longmans, Green \& Co LTD, London, 1966.

Edlefsen, N.E., and Anderson, A.B.C., Thermodynamics of soil moisture, Hilgardia, vol. 15, pp. 31-298, 1943.

Escalona, I.G., Gommes, C.J., Job, N., Blacher, S., Olivera-Fuentes, C.G., Pirard, J.P., and Léonard, A., Water desorption from resorcinol-formaldehyde hydrogels and adsorption in the resulting xerogels, Microporous and mesoporous materials, vol. 117, pp. 61-66, 2008.

Ferro-Fontan, C., Chirifa, J., Sancho, E., and Iglesias, H.A., Analysis of a model for water sorption phenomena in foods, Journal of Food Science, vol. 47, pp. 1590-1594, 1982.

Fredlund, D.G., and Xing, A., Equation for the Soil-Water Characteristic Curve, Canadian Geotechnical Journal, vol. 31, pp. 521-532, 1994.

Guggenheim, E. A., Thermodynamique, Dunod, Paris, 1965.

Iwata, S., Tabuchi, T., and Warkentin, B.P., Soil-water Interaction: Mechanisms and applications, 2nd Edition, Lavoisier Pub., France, 1995.

Jamin, F., El Youssoufi, M.S., and Saix, C., On the thermo-extensive nature of the yield surface for an unsaturated soil, Comptes Rendus de Mécanique, vol. 332, pp 153-159, 2004.

Job, G., and Hermann, F., Chemical potential, a quantity in search of recognition, European Journal of Physics., vol. 27, pp. 353-371, 2006. 
Koorevaar, P., Menelik, G., and Dirksen, C., Elements of Soil Physics, Elsevier, New-York, 1983.

Leong, E.C., and Rahardjo, H., Review of soil-water characteristic curve equations, Journal of Geotechnical and Geoenvironmental Engineering., vol. 123, pp. 1106-1117, 1997.

Low, P.F., Concept of total potential in water and its limitations: A critique, Soil Science, vol. 91, pp. 303-305, 1961.

Morel-Seytoux, H.J., Meyer, P.D., Nachabe, M., Touma, J., van Genuchten, M.T., and Lenhard, R.J., Parameter equivalence for the Brooks-Corey and van Genuchten soil characteristics: preserving the effective capillary drive, Water Resources Research, vol. 32, pp. 1251-1258, 1996.

Mrani, I., Bénet, J.-C., and Fras G., Transport of water in a biconstituant elastic medium, Applied Mechanics Reviews, vol. 48, pp. 717-721, 1995.

Müller, I., Thermodynamics of mixture and phase field theory, International Journal of Solids and Structures, vol. 38, pp. 1105-1113, 2001.

Nitao, J.J., and Bear, J., Potentials and their role in transport in porous media, Water Resources Research, vol. 32, pp. 225-250, 1996.

Ouoba. S., Cherblanc, F., Cousin, B., and Bénet, J.-C., A new experimental method to determine the sorption isotherm of a liquid in a porous media, Environmental Science \& Technology, vol. 44, pp. 5914-5919, 2010.

Ponsart, G., Vasseur, J., Frias, J.M., Duquesnoy, A., and Méot, J.M., Modelling of stress due to the shrinkage during drying of spaghetti, Journal of Food Engineering, vol. 57, pp. 277285.2003.

Salager, S., El Youssoufi, M.S., and Saix, C., Effect of temperature on water retention phenomena in deformable soils: theoretical and experimental aspects, European Journal of Soil Science, vol. 61, pp. 97-107, 2010.

Sih, G., and Michopoulos, J., Hygrothermoelasticity, Martinus Nijhoff publishers, 1986. 
Timmermann E.O., Chirife J., and Iglesias H.A. Water sorption isotherms of food and foodstuffs: BET or GAB parameters?, Journal of Food Engineering, vol. 48, pp. 19-31, 2001. 